\title{
Entrevista com Stefan Kaegi ${ }^{1}$
}

\section{Interview with Stefan Kaegi}

Maicyra TELES LEÃO E SILVA ${ }^{2}$

\section{Resumo:}

A entrevista ${ }^{3}$ versa sobre aspectos do processo criativo e de produção do theatermacher [fazedor de teatro] Stefan Kaegi, integrante do grupo de diretores alemão Rimini Protokoll. Aborda questões referentes ao que chama de Reality Trend, fricionando dimensões do real e do ficcional na cena, com enfoque especial para obras desenvolvidas pelo entrevistado, no Brasil.

Palavras-chave: Teatro Documentário, processo criativo, processo conceitual

\section{Abstract:}

The interview deals with aspects of the creative process and production of the theater maker Stefan Kaegi, member of the German collective Rimini Protokoll. Addresses issues related to what they call Reality Trend, rubbing dimensions of the real and the fictional in the scene, with special focus on works undertaken by the respondent in Brazil.

Keywords: Documentary theater, creative process, conceptual process
1. Artista, produtor e articulador, integrante do coletivo de diretores alemão Rimini Protokoll. Cria obras de Teatro Documentário, Projetos de mapeamento da cidade e condução via áudio e rádio, Shows de rádio e trabalha na esfera urbana, a partir de uma variedade de parcerias. Utilizando-se de pesquisas, audiências públicas e processos conceituais, ele dá voz a "especialistas" que não são treinados para serem atores, mas têm algo a dizer. Desde 2003, o Rimini Protokol está vinculado ao Hebbel am Ufer HAU, em Berlim, Alemanha.

2. Professora Adjunta do Núcleo de Teatro da Universidade Federal de Sergipe, doutora pelo Programa de Pós Graduação em Artes Cênicas da Universidade Federal da Bahia e Mestre em Arte Contemporânea, pela Universidade de Brasília.

E-mail:maicyraleao@gmail.com

3. Entrevista realizada em maio de 2013, em Berlim, como parte da pesquisa doutoral da entrevistada intitulada "Poéticas do Convívio: processos performativos do si ao compartilhamento", viabilizada através de Bolsa de Estágio Doutoral no exterior oferecida pela CAPES. 


\section{Nota Introdutória}

Stefan Kaegi é integrante do coletivo de diretores alemão Rimini Protokoll. Criado em 2000, em Gießen e hoje sediados em Berlim, o coletivo é formado atualmente por Stefan Kaegi, Helgard Haug e Daniel Wetzel, e destaca-se pela diversidade de produções envolvendo pesquisas de campo ou com comunidades específicas, que apresentam narrativas no palco ou em lugares alternativos por meio dos próprios sujeitos-fontes. Apesar de insistentemente serem rotulados como praticantes de um Teatro Documentário, seus integrantes refutam a afirmação e defendem sua prática como relacionada ao Reality Trend, mais próxima, por sua vez, de um teatro praticado por experts, como chamam os especialistas envolvidos em suas encenações, ou seja, a partir da apropriação direta de agentes externos ao universo artístico, na realização de seus projetos.

Sendo um grupo formado por diretores, por sua vez, os integrantes ora trabalham juntos ora individualmente ou com outras parcerias e, no Brasil, desenvolveram três projetos, todos eles dirigidos por Kaegi. São eles: Chácara Paraíso- Mostra de Arte Polícia (2007), em parceria com a diretora argentina Lola Arias, sobre a corporação policial paulista; Torero Portero ${ }^{9}$ (2005), um projeto sobre porteiros de edifícios, também em parceria com Arias; e Matraca Catraca (2002), sobre motoristas de ônibus.

O primeiro deles, projeto de maior vultuosidade do grupo, no Brasil, foi desenvolvido a partir de um dedicado estudo de campo no local homônimo, Chácara Paraíso, onde se encontra o maior centro de formação de soldados da Polícia Militar, na América Latina, no bairro de Pirituba, São Paulo. Kaegi e Arias visitaram centros de formação e treinamento, cerimônias de formatura, centros de atendimento psicológico, cavalarias, - Corpo Musical e até a capela da Polícia Militar e, durante este percurso, sugeriram um evento artístico, ocorrido no $14^{\circ}$ andar do Edifício Sede do SESC-SP, em reforma na época.

No evento, uma imagem heterogênea e ambivalente da instituição policial, junto aos depoimentos realizados com a presença real desses indivíduos pesquisados, fotos e outros documentos eram utilizados na reconstituição desse material, não numa tentativa de estabelecer "tratados sociológicos ou históricos sobre a instituição policial, mas discursos menores constitutivos do real e pertencentes e potentes, colunas mestras e ocultas de sustentação de todo o sistema" (KAEGI; ARIAS, 2007 : 57). Ainda, a presença física desses especialistas configurava justamente o sentido de heterogeneidade proposto pelas justaposições dos diversos pontos de vistas, que se confrontavam ao dividir o mesmo ambiente-situação, conferindo estranheza à ficção das cenas construídas.
9. O primeiro, Matraca Catraca, foi desenvolvido em 2002, e este segundo em 2005 
Assim, Stefan se afirma "um curador da realidade". Nesse sentido, indica o lugar central de sua criação mesclado a um tipo de método de seleção de material humano que se aproxima de técnicas de apropriação, conforme anuncia o crítico Ricardo Muniz ao intitular esse procedimento como um "ready-made 4 teatral", no catálogo de Chácara Paraíso. Ele utiliza esses especialistas como um dispositivo de conexão com uma história mais ampla relacionada ao contexto específico que pretende expor, apesar desse contexto ser apresentado de forma descontextualizada. Nesse sentido, tensiona questões relacionadas a dimensões do real e do ficcional, além de fundir discursos de esferas particulares e corporativas, fricionando o dado testemunhal.

Maicyra Leão - Como você gosta de ser chamado? Você gosta de ser apresentado como diretor teatral? Como você se intitula?

Stefan Kaegi - Eu acho que o termo que eu mais uso é diretor, mas pode-se dizer também Theatermacher, ou seja, fazedor de teatro, mas em português é um termo que soa feio. Mas é um termo mais amplo, porque dirigir a peça, no sentido clássico, é apenas uma parte do que eu faço. Investigador seria o ponto certo; ou como autor, de certa forma também; ou editor de peças; ou location scouter; ou também produtor, porque tem um pouco de tudo isso. Ghostwriter também. Todas essas funções, de alguma forma, entram no meu esquema.

ML - Então o termo em alemão cabe melhor?

SK - Sim. Porque você pode ter uma formação como diretor de teatro que não tem nada a ver com esse meu esquema, como é o caso, por exemplo, da maioria dos diretores de teatro formados aqui na Ernst Hochschule ${ }^{5}$. Eles são habilitados a pôr em cena peças de teatro que já existem em texto e isso está longe do que eu faço.

ML - Brevemente, você poderia me relatar seu percurso/ carreira profissional, para além dos títulos oficiais?

SK - Existe uma parte relevante que ficou em mim vinda do jornalismo, que foi meu primeiro trabalho. Depois eu passei um tempo estudando Artes Plásticas, mas no fim achei meio chato porque entendi que lá você vai sempre tratar com uma certa sacralização do objeto, da pessoa, ou do artista e achei isso demasiadamente voltado para o campo comercial, de alguma forma, já que tem que se preocupar em vender algo. Então, achei mais atrativo o desafio de criar entertainment, mas redefinir o que pode ser entertainment: que não é o well made play; que não é uma narração que te faz esquecer os pro-
4. Termo bastante utilizado nas Artes Visuais para referir-se à apropriação de objetos do universo cotidiano transferidos para o contexto da arte. Ficou emblematizado com o trabalho de Marcel Duchamp, A Fonte, no qual assina um mictório comum de um banheiro masculino e o expõe no ambiente artístico anunciando-o como objeto de arte.

5. A Ernst Busch Academy of Dramatic Art - Berlin é um dos mais antigos centros de formação especializada em Berlim, tendo sido criado como Conservatório de Interpretação, em 1905, e ganhando o status de Universidade, em 1981. A Universidade hoje é um dos principais centros de referência de formação em Artes Cênicas da Alemanha e é formada por quatro departamentos: Interpretação, Direção, Animação e Dança. 
blemas; que não são textos de autores mortos. Mas eu sempre gostei da concentração que existe no fazer teatral.

$M L$ - E nesse percurso, seja no jornalismo, no teatro, na vida ordinária- literária-familiar, existe alguma/algumas influências que você identifica claramente?

SK - Meu professor de física. Eu acho ele um bom performer. Ele fez experimentos, explodiu coisas e sempre queria nos explicar sobre coisas que não podíamos ver. Mas ele as tornava visualizáveis com coisas que ele tinha à mão e eram espetaculares.

SK - Mas você queria falar dos trabalhos itinerantes, não?

$M L$ - Sim.

SK - Porque essa semana uma de minhas alunas no workshop ${ }^{6}$ (Helena, vinda da região do extremo nordeste da Rússia) falou para mim "Stefan, você é um Stalker". Fazendo referência ao protagonista do filme homônimo do Tarkoswki, em que o personagem vai na frente e ele leva um grupo de pessoas a um território que por alguma razão já não tem sobreviventes. E esse eu achei um bom termo para definir o meu trabalho. Não um diretor. É porque a combinação entre fazer esses projetos itinerários tem a ver com a minha condição de vida, cigano de certa forma, já que durante oito anos, eu não tinha casa fixa, minha casa era minha mala, e digeria as coisas no trem e em viagens. Então, muitas de minhas obras tem essa forma de viagem, percurso, e mesmo minhas peças que são feitas em cenários como por exemplo Bodenprobe Kasaschstan ou Mnemopark -um trabalho que fiz com mini trens - eles têm a ver com viagens. Por meio do vídeo também você viaja por alguns territórios.

$M L$ - E esse período de oito anos, foi anterior ao período que estava na universidade?

SK - Na verdade, posterior, pois não cheguei a concluir o curso, já que já estava envolvido com viagens de trabalho.

ML - E como você foi morar em Blumenau? Você tinha algum interesse particular no Brasil?

SK - Por meio de intercâmbio cultural. Eu não tinha interese no Brasil. Eu queria aprender espanhol, mas me mandaram para o Brasil.

$M L$ - Em relação aos outros integrantes do Rimini em quais aspectos vocês se aproximam e se distanciam?

SK - Estamos sempre equidistantes. Sempre fazemos trabalhos juntos e trabalhos separados.

$M L$ - Mas você identifica algum tipo de qualidade específica de seu trabalho, seja poética ou relacionada aos tipos de procedimentos, que te aproxima ou distancia do trabalho deles?
6. Refere-se ao Workshop que estava desenvolvendo no Theater Treffen - Encontro Anual de Teatro Alemão. 
SK - Sim. Eu acho que essas coisas mais itinerantess são mais uma especialidade minha. Talvez Call Cutta também tinha isso na sua versão itinerante, mas de todo modo eu já tinha feito trabalhos de áudio antes desse, e me concentrei nisso; como o trabalho com bicicletas, o trabalho com caminhões - Cargo Sofia; o trabalho com ônibus em Salvador da Bahia - Matraca Catraca.

$M L$ - Eu sempre acho difícil explicar e definir o tipo de trabalho que você faz e nessa tentativa acabo sempre descrevendo obras. Quando você precisa explicar o seu tipo de trabalho a pessoas leigas em relação ao teatro, como acha melhor fazer?

SK - Faço como você: eu dou um exemplo. Pode ser mais difícil, pode ser mais fácil. Existem trabalhos documentários que têm um assunto muito claro, como usinas ou petróleo, ou relação com o capital, ou partem da reconstrução de peças históricas. Esses são trabalhos que talvez sejam um pouco mais fáceis de explicar. Já os trabalhos mais interativos são mais complicados porque dependem do público. Então é como explicar um jogo. É o caso, por exemplo, desse trabalho que estamos produzindo agora sobre tráfico de armas, Situational Rooms, onde há a utilização de Ipads mini como parte da experiência. Mas de toda forma acho mais fácil falar sobre as experiências das nossas obras do que as obras que você vê no Theater Treffen ${ }^{7}$ (TT), na maioria das vezes, porque se você explica o que uma peça do TT faz, parece muito chato. Muitas vezes é, mas muitas vezes não é. Você pode dizer que é uma peça com tal estrela, que é uma atriz incrível e etc, mas se você quer descrever qual é a qualidade que ela tem, acho mais difícil. Enquanto que um conteúdo interessante como uma experiência de caminhar, não acho tão complicado explicar de um modo que alguém que não tenha nada a ver com teatro não compreenda porque isso pode ser legal.

$M L$ - Tenho a impressão que você trabalha muito com o formato sobre como apresentar o trabalho. Por exemplo, o Remote Berlin, é mais fácil explicar o formato de como a peça acontece: um áudio pré-gravado que conduz o ouvinte por espaços da cidade. Você identifica isso?

SK -Sim. Mas com a produção também. Trabalho muito sobre como poder viajar com uma peça sem ter que transportar muita cenografia e elementos grandes.

$M L$ - Isso fica claro também na estrutura do Festival Ciudades Paralelas.

SK - Então, esses projetos nascem também, de alguma forma, por terem uma ligação com os meios de produção, que por sua vez precisam inventar modos nesse campo. Nós não temos um teatro fixo onde produzimos, onde já temos sub-
7. Festival realizado anualmente em Berlim, reunindo seleção das melhores produções teatrais dos países de língua alemã, na opnião de um comitê julgador, que tenham estreado no ano anterior. 
sídios garantidos. Nós temos que buscar subsídios. Assim, a conceptualização clara do que queremos fazer é importante já que, na busca pelos subsídios, temos que colocar o projeto no papel um ano antes de começar a trabalhar, para, a partir daí, saber se podemos dar continuidade ou não.

$M L$ - Nesse sentido, a institucionalização que existe aqui, com ensembles específicos, diferencia-se da realidade brasileira. Você entende que essa condição relacionada a busca por subsídios que acabou de relatar, torna a obra um Projeto, no sentido que ganha uma amplitude em termos de acontecimento teatral, para além de apenas ser uma apresentação?

SK - Sim. Eu acho que um projeto como o Cem porcento cidade $^{8}$ pode ser considerado uma escultura social também, porque envolve pessoas da cidade inteira e cem pessoas, por fim, estarão no palco. E como eles estão procurando no meio das casas, a cidade inteira torce para encontrar aqueles que ainda faltam para justificar a sessão, para espelhar as estatísticas da cidade. Então, o processo não é apenas o produto que você tem no cenário, mas também na platéia você tem um reflexo do que se tem no cenário. Vem muitas pessoas para o teatro que normalmente não iriam. Conhecem talvez uma pessoa lá, mas os outros não. Então é também uma forma de recombinação de diferentes nichos antropológicos da cidade.

ML - Você acha que seu trabalho também tem a ver com o de etnógrafo?

SK - Não entendo muito da etnografia em si, mas imagino que sim. Provavelmente sim.

$M L$ - Seu interesse teatral no Brasil, aconteceu apenas por conta do domínio da língua ou você tinha algum outro interesse profissional específico?

SK - Bom, por causa de meu passado, eu tinha um interesse de voltar ao Brasil, mas além disso eu sempre achei que lá há uma espontaneidade muito grande e uma vontade de aparecer. Vergonha, digamos assim, não é um dos atributos do Brasil. Então, sei lá, se você procura cem pessoas em Salvador que queiram aparecer no palco, no Brasil, vai ser muito mais fácil do que no Japão. Difícil é saber se de fato eles vão aparecer depois, mas eles vão dizer que sim, facilmente. Então, essa forma de ser aberto e também ter um certo orgulho de sua figura, sua voz, sua maneira de ser, acho que isso já é interessante para quem trabalha como eu, porque eu chego lá na polícia de São Paulo e começo a falar com policiais e eles não tem necessariamente medo. Aliás, tem medo do superior, se ele vai deixar ou não, se ele vai autorizar... Essas coisas são muito complicadas, mas eles pessoalmente podem facilmente se imaginar protagonistas. E isso foi uma ajuda pra mim,
8. Neste projeto, o Rimini Protokoll convida 100 pessoas para apresentarem a cidade por meio de sua própria perspectiva. Assim, no palco, esse coro revela uma cidade pouco conhecida, mas ao mesmo tempo repleta de efeitos de pertencimento. De acordo com a definição ou questionamentos propostos pelo próprio grupo: Quem está faltando? Que tipo de relato surge no palco diferente de pesquisas quantitativas? $\mathrm{O}$ que as estatísticas não conseguem registrar? Quem imagina que a cidade pode ser diferente uma vez que você é parte dela? O projeto já foi realizado em diversas cidades como Filadélfia, Penang, Paris, Tóquio, Krakóvia, São Diego, Dresden, entre as mais recentes. 
porque se fosse em algum outro país talvez seria muito mais difícil conseguir a colaboração.

ML - Quando você começou a atuar no Brasil?

SK - O primeiro projeto foi Matraca Catraca. Ah! Mas antes, nós viemos com uma peça argentina chamada Torero Porteiro, com porteiros argentinos, e associamos, no Brasil, um porteiro paulista que contou uma história sobre como era sua profissão no Brasil.

$M L$ - Isso aconteceu em um contexto de festivais?

SK - No Rio sim, mas em São Paulo não. No Rio, o festival na época chamava Rio em Cena, mas é esse mesmo festival que modificou o nome algumas vezes.

ML - De lá para cá, você sente muita diferença na produção teatral brasileira?

SK - Claro que sim. As condições de trabalho se modificaram enormemente. No Congresso da $A B R A C E^{10}$ (2010), por exemplo, onde nos encontramos, existiam cerca de oitocentas pessoas participando e pesquisando teatro. Isso era impensável na época em que eu fiz Matraca Catraca, onde tinham muito poucas pessoas estudando teatro e que poderiam sobreviver de teatro. Talvez um pouco mais em São Paulo. Ocorreu uma mudança econômica significativa no país e, além disso, a implantação de uma legislação que ampliou a necessidade de mais professores de teatro também nas escolas e na área de educação.

ML - Tem algum grupo no Brasil que você tem interesse específico em trabalhar, seja ele teatral ou social?

SK - Eu tenho vontade de trabalhar sobre políticos brasileiros. Porque esse é um campo que se modificou muito no Brasil. Eu lembro, em 1989, que quando eu estava em Blumenau, eu torcia pelo PT (Partido dos Trabalhadores), mas parecia longe de ser uma realidade que Lula pudesse ser presidente, mesmo que ele tenha chegado ao $2^{\circ}$ turno na época. $E$ eu acho interessante o que aconteceu. Diferentemente, na Argentina, hoje em dia, eles seguem mais ou menos com a atitude presente em 2001, quando houve a crise econômica e a Argentina teve três presidentes em um ano. Na Argentina, as pessoas não acreditam mais em política e, no Brasil, acho que sim. Há pessoas que entram no partido com uma visão de idealismo. Acho interessante como esse sentido se transformou. Comparativamente, a distância temporal para o período de ditadura em ambos os países é praticamente a mesma, mas é surpreendente a mudança que se desenvolveu.

$\mathrm{E}$ a outra coisa que me interessa, mas também porque me interessa aqui na Alemanha, é a Volkswagen, como a primeira indústria brasileira e Latino-Americana de enorme porte. Me
10. Associação Brasileira de Pesquisa em Artes Cênicas - ABRACE. 
interessa a conexão mista entre Hitler, por exemplo, e o socialismo, como indica o nome Volks, enquanto que hoje em dia a China é o principal mercado para ela. Eu fui visitar em São Bernardo uma fábrica e foi interessante perceber essa adaptação do rigor alemão ao modo brasileiro.

$M L$ - Com quais grupos brasileiros você acha que seu trabalho encontra alguma afinidade?

SK - Acho que essa é uma pergunta que você deveria responder, porque não conheço o suficiente para saber. Porque, também, quando vou ao Brasil eu vejo sempre teatro que não tem nada a ver com o que eu faço. Uma sobreatuação e uma necessidade de passar energia sem razão nenhuma que não entendo. Tem uma referência à televisão que não me interessa. Características que me parecem muito longe, enquanto que o teatro argentino me parece mais próximo do que nós, como europeus, podemos compreender. Acho que o público brasileiro gosta de formas de teatro que para mim não tem nenhum acesso possível de prazer, digamos. A quantidade de narcisismo é ainda muito maior no teatro do Brasil do que no da Alemanha. É difícil ser tocado.

ML - Na Argentina, então, quais afinidades você encontra? Lola Arias ${ }^{11}$ seria um bom exemplo?

SK - Eu acho que, em geral, no teatro argentino o interessante é que os grandes diretores sempre foram os autores também. A formação de teatro lá vem mais de uma experiência com elaboração de texto, então, há uma redução ao essencial digamos, quando falamos de Veronese, de Federico Leon, de Mariano Pensotti ${ }^{12}$. Apesar deles também vivenciarem essa separação, como há na Alemanha, entre diretor e autor.

ML - Com relação aos trabalhos que desenvolveu no Brasil, como você descreve a forma de abordagem que desenvolveu junto aos "especialistas"?

SK - Os três trabalhos a que você se refere, para mim, podem ser considerados como uma trilogia sobre posições de poder na América Latina, porque são figuras que exercem um certo poder, seja na catraca, seja na polícia, seja na entrada de edifício. É um poder de controle, de certo modo, que é executado onde trabalham pessoas que na verdade vem da classe baixa, que estão nessa posição de poder, mas que executam ordens de uma hierarquia vinda de uma classe mais alta. Talvez hoje em dia isso não seja bem verdade, mas na época sim.

ML - Como acontece a abordagem direta com eles? Você se apresenta a partir dessa posição de diretor de teatro?

Sim. Eu procuro as pessoas em conversas diretas ou anúncios em jornais. Eu anuncio e convido as pessoas para um
11. Lola Arias é escritora, diretora, atriz e compositora musical argentina. Fundou a companhia interdisciplinas de arte Postnuclear e dentre seus trabalhos estão: Striptease (2007), El amor es un francotirador (2007), Mi vida después (2009), Familienbande (2009) e That Enemy Within (2010). Em 2010, Arias e Stefan Kaegi fundaram o Ciudades Paralelas, um festival de performance urbana em site-specific, em Berlim, Buenos Aires, Varsóvia, Zurique e Cingapura.

12. Se refere a Daniel Veronese, Federico Leon e Mariano Pensotti, ambos autores e diretores do expoente teatro argentino, da atualidade. Apesar das diferentes abordagens e estilos, ambos exploram a situação de autoria de modo investigativo entre a criação do texto e da cena, além de investirem em interferências entre linguagens artísticas como, por exemplo, o cinema. 
trabalho, na verdade. Um trabalho que vai refletir a condição desse trabalho mesmo. Às vezes se candidatam pessoas que estão desempregadas, mas que já trabalharam nessa posição. Então, também entra a condição de ser desempregado.

ML - O Chácara Paraíso também envolveu anúncios em jornal?

SK - Não estou muito certo, mas quem me inspirou para essa peça foi na verdade um policial que conheci que era muito filosófico, que estudou Wittgenstein, por exemplo, e achei essa combinação muito louca: a coincidência em trabalhar com a arma e com um intelectual do começo do século passado. Então, ele nos ajudou muito a entrar no sistema policial.

$M L$ - E em algum desses projetos, você considera que se envolveu num convívio emocional com essas pessoas ou as relações se mantiveram num nível de clareza e objetividade para o trabalho? Pergunto isso porque nos vídeos do Chácara Paraíso, por exemplo, eu percebo um tom de entrevista bem grande. Então, de que forma você se coloca nesse ambiente? Se coloca mais nesse papel de investigador ou considera que você se mescla a essa ambiência?

SK - Acho que é como você mencionou. Iniciamos com a investigação, mas depois tem um passo em que começamos a propor coisas que um jornalista, por exemplo, não faria. $O$ que vai suceder com esse espaço, com essa música, com qual finalidade. No final, o resultado é mais do que uma entrevista. É uma performance subjetiva, talvez autêntica no sentido que tem relação com a vida deles, mas também é uma construção para mim. Uma entrevista impressa no papel, numa revista por exemplo, também é artificial, mas a situação de um público pagar para assistir algo no teatro distancia mais do autêntico, até porque também trabalhamos por bastante tempo na construção dessa realidade, desse acompanhamento. Por três ou quatro meses trabalhamos com eles e também transformamos a vida deles, porque uma coisa é retratar a realidade e a outra é construir uma realidade.

ML - Esses projetos, no Brasil, tem uma duração média de três a quatro meses?

SK - Digamos que a partir da primeira idéia, tem muito mais, um ano a um ano e meio. De realização direta, sim, de três a quatro meses.

ML - Você menciou essa construção de uma realidade. No Brasil e aqui na Europa há uma diferença bem grande em relação ao tratamento da memória e da história. Em seus projetos, seu interesse é focar no tratamento a uma história autobiográfica e particular dos envolvidos ou tem um interesse de construção ou reconstrução de uma memória com comprometimento social e histórico? 
SK - Eu acho que é sempre uma resposta subjetiva a uma história coletiva que existe. Trabalhar sobre a Polícia em São Paulo também significa trabalhar sobre fatos históricos como a invasão da USP (Universidade de São Paulo) e o desaparecimento de pessoas, por exemplo. Mas esses fatos em si não se tornam uma relidade de teatro se não tiver de alguma forma um nexo com as pessoas com as quais trabalho. Nesse trabalho, por exemplo, precisamos disso. No Remote Berlin, por sua vez, isso não é relevante porque é totalmente um outro tipo de trabalho, mas nos Documentários de alguma forma há uma substituição de uma imagem geral objetiva e distante.

$M L$ - Para finalizarmos, você acha que em seu trabalho há um pouco de voyeur?

SK - Acho que há um mal entendimento dessa palavra. É claro que teatro sempre, se você quiser, envolve um aspecto de voyeur, mas para mim o teatro voyeur é aquele em que você está sentado no escuro, olhando pessoas atuando que não estão vendo para quem estão falando. Mas de toda forma, ainda assim, também não é voyeur porque o público paga para estar ali e os atores também são pagos. O encontro com pessoas que falam de si mesmos, que tem alguma coisa para explicar sobre o que trabalhamos por meses não tem a ver com voyeur, não. Televisão tem mais a ver com voyeur porque não é visível e você observa algo que não sabe que está sendo visto. O voyeur é como aquelas pessoas que ficam no escuro assistindo pessoas se despindo em outras janelas, que não sabem que estão sendo vistas, e isso é o caso da televisão. Porque lá você tem essa distância, tem esse poder de escapar. O espaço do teatro, nesse sentido, é um espaço social, então é um ato de comunicação. Não é um ato de separação. 
KAEGI, Stefan; ARIAS, Lola. Catálogo do Projeto Chácara Paraíso - Mostra de Arte Policial. 2007. Disponível em http://www. chacaraparaiso.net/ Acesso em 05/05/14. 